\title{
Analysis of Heavy Oil Emulsion-Carbon Dioxide System on Oil-Swelling Factor and Interfacial Tension by Using Pendant Drop Method for Enhanced Oil Recovery and Carbon Dioxide Storage
}

\author{
Kreangkrai Maneeintr, Tayfun Babadagli, Kyuro Sasaki, and Yuichi Sugai
}

\begin{abstract}
Heavy oil becomes more interest owing to oil prices and the huge amount of reserves. Steam injection is a common method for heavy-oil production with emulsion formation. Also carbon dioxide injection is applied for viscosity and interfacial tension reduction. $\mathrm{CO}_{2}$ becomes more important because of environmental concerns. $\mathrm{CO}_{2}$ storage in reservoirs like depleted oil wells becomes widespread. Hence, understanding the behavior of $\mathrm{CO}_{2}$ when it encounters emulsive heavy-oil is critical. In this work, the interfacial tension and oil-swelling factors of $\mathrm{CO}_{2}$ in oil and its emulsions are measured at $296 \mathrm{~K}$ and pressure from 0.5 to $1.5 \mathrm{MPa}$ with water/oil ratio from 0.00 to 12.27 percent compared to original oil. The results show that the interfacial tension decreases at higher pressure ranging from 3.7 to 16.8 percent and water content from 10.3 to 22.6 percent. Furthermore, oil-swelling factors increase with pressure and water content up to 1.9 percent and 8.0 percent, respectively. These results are explained by absorption processes in that high pressure can serve as high driving force for $\mathrm{CO}_{2}$ solubility.
\end{abstract}

Index Terms-Heavy oil emulsion, steam and $\mathrm{CO}_{2}$ injection, interfacial tension, oil swelling factor.

\section{INTRODUCTION}

The current status of oil prices and increasing demand for oil make bitumen and heavy-oil reserves more attractive. However, although the resources of unconventional oils in the world are more than twice those of conventional light crude oil [1], limited technologies hinder their efficient production even with high oil prices.

The production of unconventional oils is difficult because of their high viscosity. Therefore, thermal recovery especially steam injection is used to produce this kind of oil. When steam is injected into a heavy oil reservoir, emulsion will be formed by involving fine water droplets in crude oil (w/o) which is often stable [2], [3]. This emulsion has essential effect on the flow behavior of heavy oil by increasing its viscosity [4], [5].

The formation of w/o emulsion is typical in thermal

Manuscript received May 25, 2013; revised September 10, 2013.

K. Maneeintr is with the Department of Mining and Petroleum Engineering, Faculty of Engineering, Chulalongkorn University, Pathumwan, Bangkok 10330, Thailand (e-mail: Krengkrai.M@ Chula.ac.th).

T. Babadagli is with the School of Mining and Petroleum Engineering, Department of Civil and Environmental Engineering, University of Alberta, Edmonton, T6G 2W2 Canada.

K. Sasaki, and Y. Sugai are with the Department of Earth Resources Engineering, Faculty of Engineering, Kyushu University, Fukuoka 8190395 Japan. recovery processes and its mechanics within the reservoir was discussed in literature [6]. With steam injection, steam condensation on cooler oil surfaces is considered as the main reason for emulsion formation in the reservoir. The tendency of oil spreading on water surfaces results in small water droplets formed by the condensation of steam to become buried within the bulk of oil.

In addition, emulsions of crude oil and water can be encountered at many stages of oil production including drilling, producing, transporting and processing of crude oils and in many locations such as in hydrocarbon reservoirs, well bores, surface facilities, transportation systems and refineries. A good knowledge of emulsions is essential to control and improve the operations. Therefore, much progress in the research of emulsions of heavy oil has been achieved in recent years with a better understanding of these systems [7]. However, many questions related to the interesting behavior of these emulsions still exist and the data for interfacial tension and oil swelling factors for emulsion of heavy oil-solvent system are rare.

Furthermore, gas injection method has been gaining more interest recently, especially injection of $\mathrm{CO}_{2}$, owing to the concern of climate change and global warming resulting from the emission of greenhouse gases. The use of $\mathrm{CO}_{2}$ in heavy oil recovery needs more investigation as it has not only enhanced the oil recovery (EOR) aspect but also storage possibility. Therefore, it is interesting to study and understand the effect of solvent on heavy oil production with emulsion.

Swelling of crude oil by any type of gas injection for viscosity reduction has been studied for decades [8]. It is beneficial for oil recovery in that it helps to reduce oil viscosity. The pendant drop volume analysis method has been used successfully to measure and calculate the diffusion coefficients and oil swelling factors of heavy oil-solvent systems [8]. The advantages of this method over the other existing ones are that a single experimental test can be achieved with less time consumption. Moreover, the measurement can be conducted at high pressure and constant temperature. Third, a solvent mixture system can be applied for this study.

Therefore, the objective of this research is to measure and investigate the effect of $\mathrm{CO}_{2}$ injection and water content in heavy-oil emulsions on oil swelling factors and interfacial tension at the different water ratio in oil and at various pressures of $\mathrm{CO}_{2}$ by applying the pendant drop volume analysis method. Another objective is to study the possibility 
of the $\mathrm{CO}_{2}$ injection method together with steam flooding to enhance heavy oil production.

\section{THEORY}

\section{A. Volume Measurement from the Dynamic Pendant Oil Drops}

The definition of the oil swelling factor is the ratio of the volume of the heavy oil saturated with the solvent to the volume of the original heavy oil without any solvent dissolution as illustrated in (1):

$$
F_{O S}=V_{t} / V_{0}
$$

where $F_{O S}$ is oil swelling factor, $V_{t}$ and $V_{0}$ are the calculated volume of the dynamic pendant oil drop at anytime $t$ and the volume of the dynamic pendant oil drop at time zero, respectively. $V_{t}$ values are obtained by using the DROPimage software (rame-hart instrument Co., USA.) linked with computer. Reference [8] illustrates the detail of volume calculation from the dynamic pendant oil drop as shown in (2):

$$
V_{t}=V_{0}+v_{\text {gas }} M_{\text {gas }} n(t)
$$

where $v_{\text {gas }}$ represents the volume change per unit mass of gas dissolved in the heavy oil emulsion- $\mathrm{CO}_{2}$ system. Moreover, $M_{\text {gas }}$ and $n(t)$ are molecular weight of gas and the number of moles of gas dissolved in the pendant oil drop, respectively.

\section{B. Interfacial Tension Measurement from the Dynamic Pendant Oil Drops}

DROPimage is a program to the measure the interfacial tensions and contact angles by image analysis in liquid-gas and liquid-liquid systems. The drop shape is determined used to calculate the interfacial tension, contact angle, area and volume of the drops. Calculation of interfacial tension is done by means of a specially developed method based on a least squares fit to theoretical profiles produced by a numerical integration of the Young-Laplace equation [9].

To determine the interfacial tension, first, size parameters $R_{0}$ and $\beta$ are determined from the drop profile, secondly interfacial tension $(\gamma)$ is calculated from these parameters by the (3):

$$
\gamma=\Delta \rho g R_{0}^{2} / \beta
$$

where $\Delta \rho$ is the mass density difference between the drop and the surrounding medium, $g$ is the gravity constant, $R_{0}$ is the radius of curvature at the drop apex and $\beta$ is the shape factor.

\section{EXPERIMENTAL SECTION}

\section{A. Material and Equipment}

The crude oil for this study was obtained from a field in the Lloydminster area in Canada. Its density and viscosity were $964 \mathrm{~kg} / \mathrm{m}^{3}$ and $8 \mathrm{~Pa} . \mathrm{sec}(8000 \mathrm{cP})$ at $298 \mathrm{~K}$, respectively. The asphaltene composition was $14-18$ percent. Emulsion was produced by injecting steam into oil using a steamer. The water/oil ratio was calculated by measuring the amount of oil and water injected in mass percent. $\mathrm{CO}_{2}$ was supplied from Praxair Inc. with 99 percent purity.

An interfacial tension cell (IFT) (Model 10, Temco, USA.) with transparent windows was used for this study. The chamber volume of the IFT was $4.15 \times 10^{-5} \mathrm{~m}^{3}$ and the maximum working pressure and temperature were $69 \mathrm{MPa}$ (or $10,000 \mathrm{psi}$ ) and $450 \mathrm{~K}$ (or $350^{\circ} \mathrm{F}$ ), respectively. Heavy oil was fed to the system through a stainless steel sample cylinder (Swagelok, Model304L-HDF2-40) by using a programmable syringe pump (Model LC 5000, ISCO Inc., USA.). The pendant oil drop can be formed by means of a stainless steel syringe needle connected with IFT. A temperature controller was connected to the IFT cell to control the temperature. The pressure inside the IFT cell was measured by a pressure gauge (Swagelok, Model PGI 63 ranging from 0-6.89 $\mathrm{MPa}(0-1000 \mathrm{psi})$ with \pm 1.5 percent of span accuracy.

A light source was used to provide the uniform light intensity for the pendant drop inside the cell. A camera (Pentax, rame-hart instrument Co., USA.) was connected to a computer with DROPimage Software to take the sequential digital pictures of the pendant oil drop and to analyze the volume and other properties such as interfacial tension and surface area of the drop for 10 images and the average value was calculated for volume analysis. All equipment was located on a vibration-free table. Fig. 1 showed the schematic diagram of the experimental setup and the pendant drop volume analysis equipment.

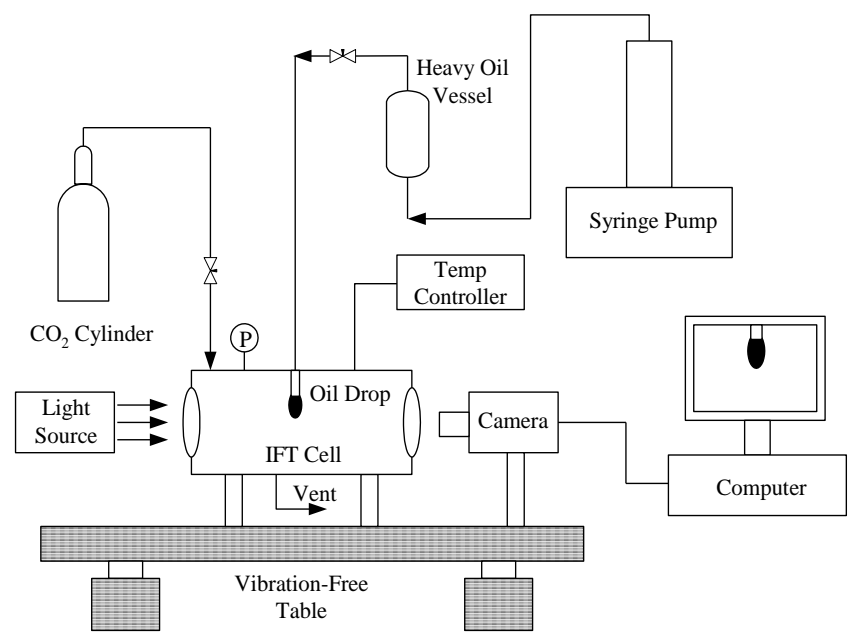

Fig. 1. Schematic diagram of pendant drop volume analysis equipment.

\section{B. Experimental Procedure}

Initially, $\mathrm{CO}_{2}$ was purged to the cell for 10-15 minutes to eliminate air and other gases. The solvent gas $\left(\mathrm{CO}_{2}\right)$ was introduced to the system until the desired $\mathrm{CO}_{2}$ pressure was reached. The system kept the pressure and temperature constant. Then, a heavy oil sample was fed to the system by a programmable syringe pump to form a pendant oil drop at the tip of the needle as shown in Fig. 2. Once the drop was formed, a DROPimage program was executed to measure and analyze the image for the volume of the drop. This process was repeated 10 times to get the average result. The image 
was taken and the measurement was repeated every 3 minutes for 90 minutes to complete the experiment. The operating conditions for this study were presented in Table I.

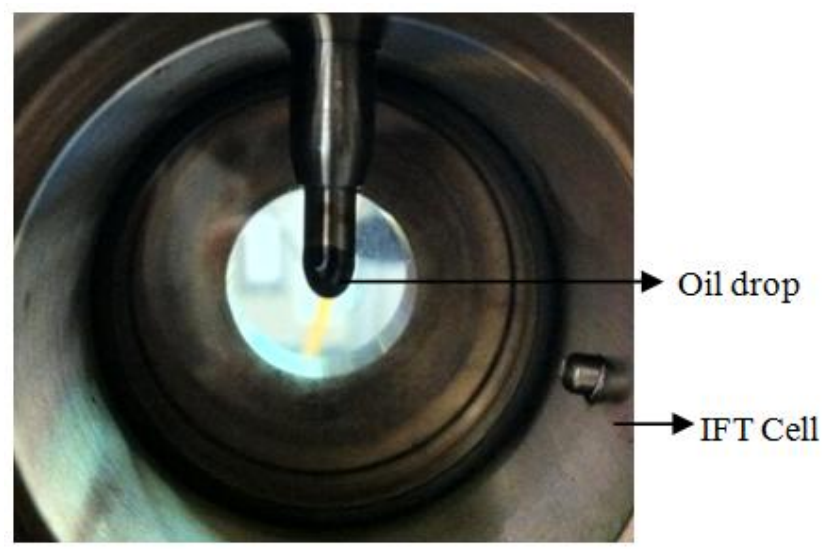

Fig. 2. Photograph of oil drop in IFT cell.

TABLE I: OPERATING CONDITIONS FOR OIL/EMULSION-CO ${ }_{2}$ MEASUREMENT

\begin{tabular}{lc}
\hline \multicolumn{1}{c}{ Oil swelling study } & Operating conditions \\
\hline Type of solvent & $\mathrm{CO}_{2}$ \\
Water/ oil ratio $(\%)$ & $0.00,3.56,8.64$ and 12.27 \\
Pressure of $\mathrm{CO}_{2}(\mathrm{MPa})$ & $0.5,1.0$ and 1.5 \\
Temperature $(\mathrm{K})$ & 296 \\
Duration $(\mathrm{min})$ & 90 \\
\hline
\end{tabular}

\section{RESUlTS AND DISCUSSION}

\section{A. The Dynamic Pendant Oil Drop Analysis}

Dynamic volumes are obtained by using the software package and are calculated every 3 minutes when gas dissolved into oil and made oil drop larger. Consequently, volume ratio can be calculated for each measurement. The measured dynamic volume ratio, i.e., $\mathrm{V}_{\mathrm{t}} / \mathrm{V}_{0}$, versus time for the heavy oil- $\mathrm{CO}_{2}$, and emulsion- $\mathrm{CO}_{2}$ systems for this study are shown in Fig. 3. From the figures, it is evident that the volume ratio of the dynamic pendant oil drop increases faster at the beginning and then it becomes slower until it approaches a certain value or equilibrium volume. More $\mathrm{CO}_{2}$ dissolves into the pendant oil drop as the molecular diffusion process continues until it is saturated with $\mathrm{CO}_{2}$. Furthermore, at higher pressure, volume ratio is larger than that of at lower pressure because of the larger driving force for $\mathrm{CO}_{2}$ diffusion in oil.

For an interfacial tension, the measured dynamic IFTs of the heavy oil- $\mathrm{CO}_{2}$, and emulsion- $\mathrm{CO}_{2}$ systems versus time at various pressures are shown in Fig. 4. From the figures, it can be concluded that the dynamic IFT reduction is caused by the increased pressure and solubility of $\mathrm{CO}_{2}$ into the pendant oil drop surface. The IFT is slightly reduced at the beginning and then remains constant. When the water content was higher, the dynamic IFT is almost constant from the very beginning. This means that the pendant drop and $\mathrm{CO}_{2}$ can quickly reach the equilibrium state [10].

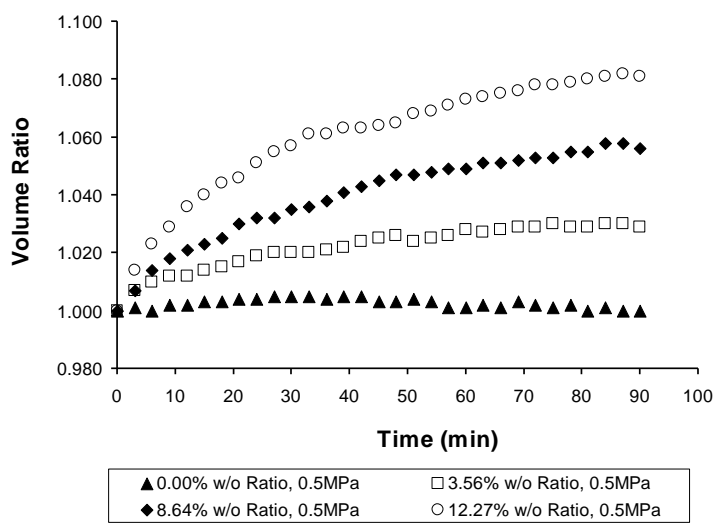

Fig. 3(a). Measured dynamic volume ratio of oil/emulsion-CO2 system versus time at pressure $0.5 \mathrm{MPa}$.

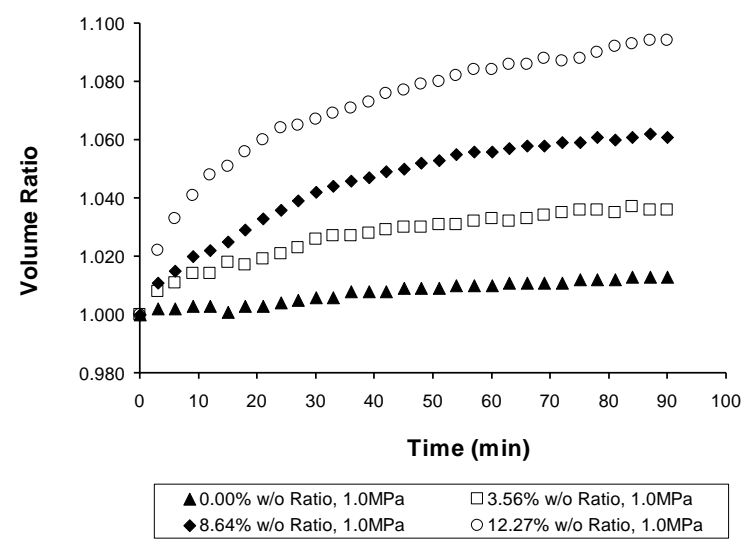

Fig. 3(b). Measured dynamic volume ratio of oil/emulsion- $\mathrm{CO}_{2}$ system versus time at pressure 1.0 Mpa.

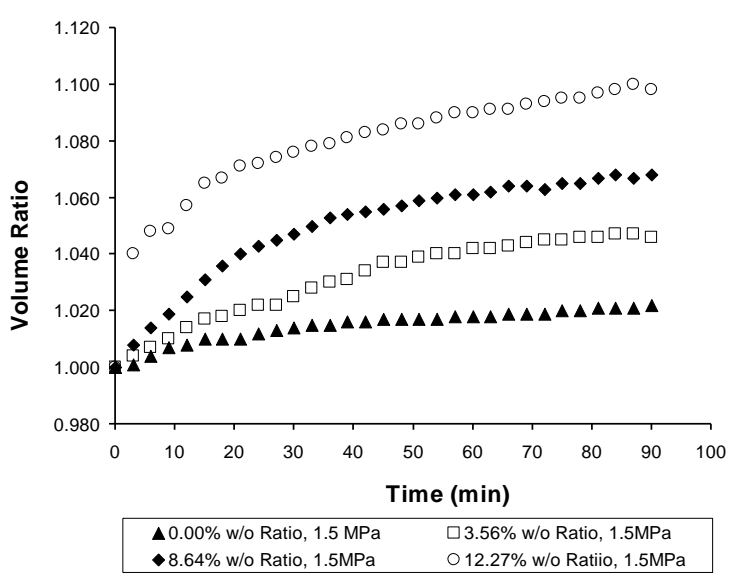

Fig. 3(c). Measured dynamic volume ratio of oil/emulsion- $\mathrm{CO}_{2}$ system versus time at pressure $1.5 \mathrm{Mpa}$.

\section{B. Effect of Pressure on Oil Swelling Factor and Interfacial Tension}

The pressure used for this research ranges from 0.5 to 1.5 MPa. Fig. 5 presents the experimental results of the effect of pressure on the oil swelling factor of the oil and its emulsion. More $\mathrm{CO}_{2}$ dissolves into the pendant oil drop by molecular diffusion until it reaches equilibrium at that condition. The process of $\mathrm{CO}_{2}$ diffusion into oil is considered a physical absorption process which is strongly dependent on the pressure of $\mathrm{CO}_{2}$ without any chemical reactions [11]. Therefore, the oil swelling factors of the heavy oil- $\mathrm{CO}_{2}$ and emulsion- $\mathrm{CO}_{2}$ systems increase with pressure because the 
higher driving force or the pressure of $\mathrm{CO}_{2}$ is applied. The more $\mathrm{CO}_{2}$ can be dissolved in oil and emulsions and the more the volume of oil and emulsions can be increased. It is evident that the relationship of oil swelling factor is related with $\mathrm{CO}_{2}$ pressure corresponding to the physical absorption principle.

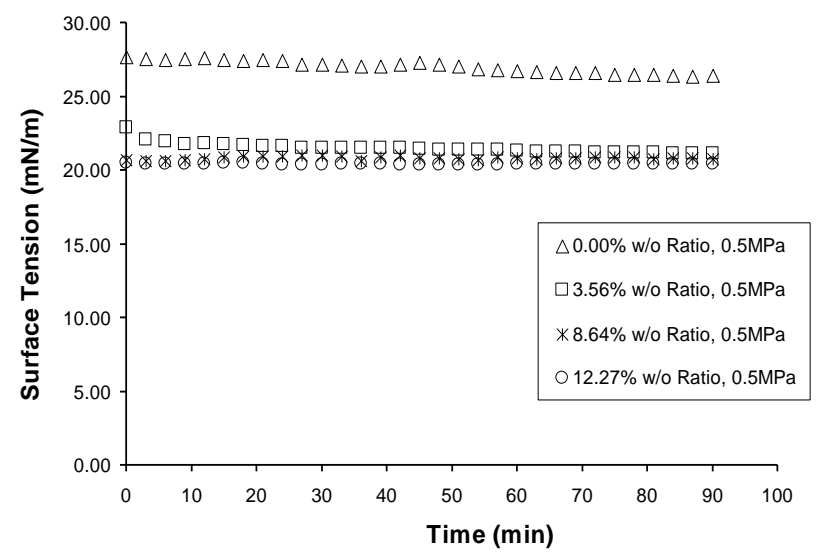

Fig. 4(a). Measured dynamic IFTs of oil/emulsion- $\mathrm{CO}_{2}$ system versus time at pressure $0.5 \mathrm{MPa}$.

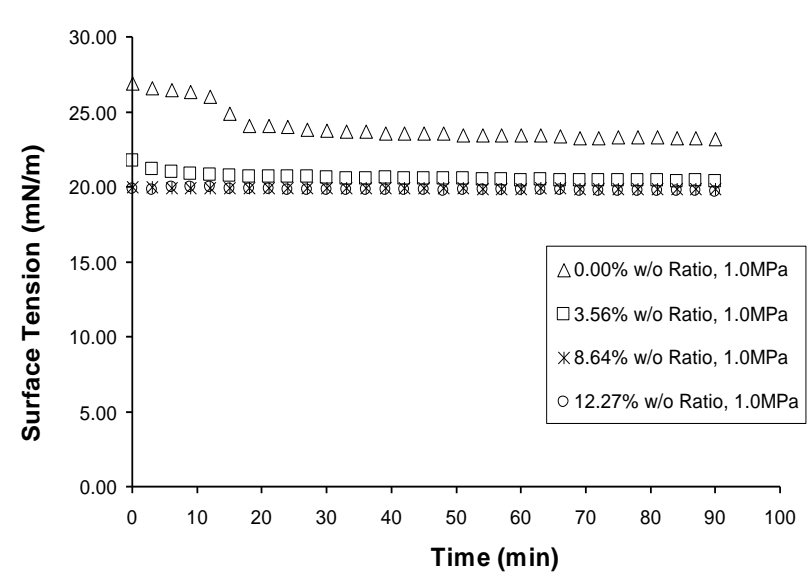

Fig. 4(b). Measured dynamic IFTs of oil/emulsion- $\mathrm{CO}_{2}$ system versus time at pressure 1.0 Mpa.

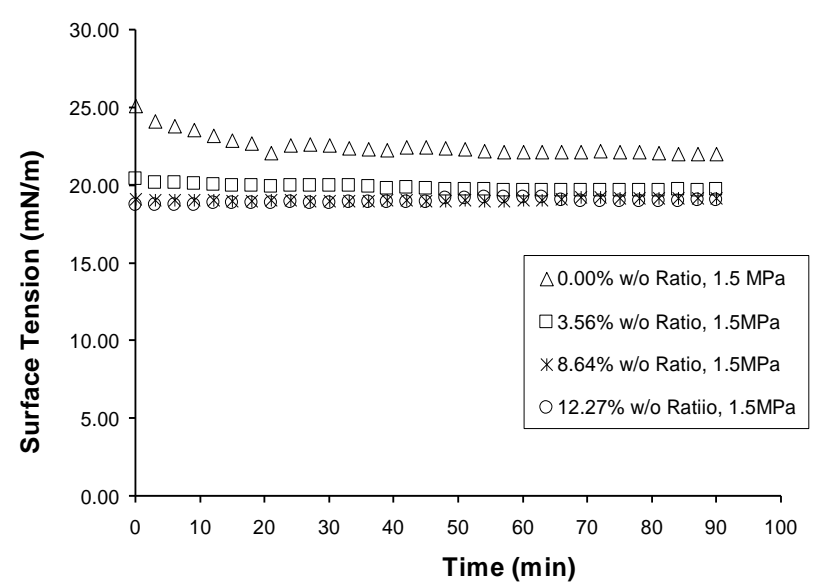

Fig. 4(c). Measured dynamic IFTs of oil/emulsion- $\mathrm{CO}_{2}$ system versus time at pressure $1.5 \mathrm{Mpa}$.

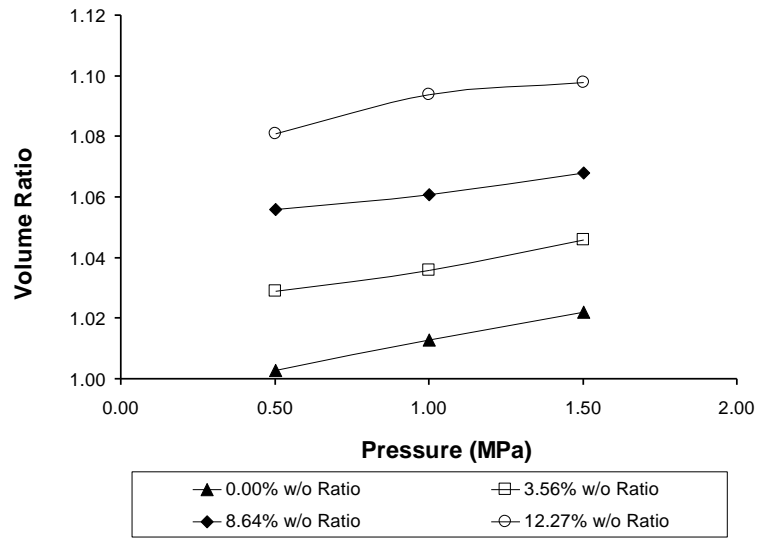

Fig. 5. Effect of pressure on equilibrium volume ratio of oil/emulsion- $\mathrm{CO}_{2}$ system.

The equilibrium IFTs of the heavy and emulsion- $\mathrm{CO}_{2}$ system at different pressure and water content are plotted in Fig. 6. This figure shows that the equilibrium IFT generally decreases as the pressure increases from 3.7 to 16.8 percent because $\mathrm{CO}_{2}$ solubility in the oil drop is higher at a higher pressure.

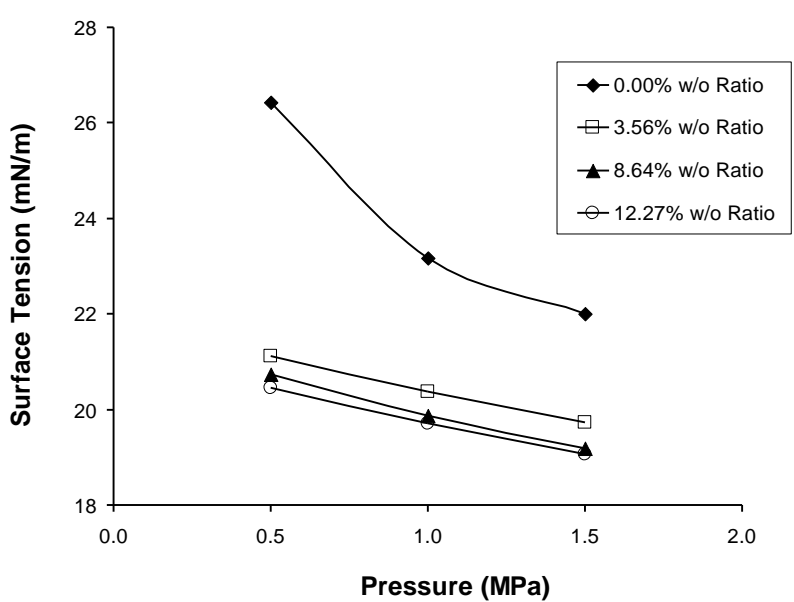

Fig. 6. Effect of pressure on equilibrium IFT of oil/emulsion- $-\mathrm{CO}_{2}$ system.

\section{Effect of Water Content on Oil Swelling Factor and Interfacial Tension}

The results of the effect of water content on oil swelling factors and interfacial tension are shown in Fig. 7 and 8 as volume ratio at different water contents and at the pressures of $0.5,1.0$ and 1.5 MPa, respectively. The amount of water in oil or water contents used in the present measurements are 0.00 (original heavy oil), 3.56, 8.64 and 12.27 percent w/o ratio by mass compared with the original heavy oil.

The plots reveal that oil swelling factors increase with water content and, interfacial tension decreases as water content increases like the effect of pressure. The percent difference of oil swelling factor and interfacial tension at different water content ranges from 1.9 to 8.0 percent and from 10.3 to 22.6 percent, respectively. This means that water in oil or emulsion from the steam injection process can be conducive to $\mathrm{CO}_{2}$ absorption in oil and increases the oil swelling factor and reduces interfacial tension. The mechanism of effect of water on $\mathrm{CO}_{2}$ dissolution in water is explained below. 
As mentioned above, the $\mathrm{CO}_{2}$ dissolution process is physical absorption without any chemical reactions. However, when $\mathrm{CO}_{2}$ dissolves in water, chemical absorption occurs. The principal reactions of $\mathrm{CO}_{2}$ with water occurring when $\mathrm{CO}_{2}$ absorbed in water may be represented as shown below [12]:

Dissociation of water:

$$
\mathrm{H}_{2} \mathrm{O} \leftrightarrow \mathrm{H}^{+}+\mathrm{OH}^{-}
$$

Hydrolysis of $\mathrm{CO}_{2}$ :

$$
\mathrm{H}_{2} \mathrm{O}+\mathrm{CO}_{2} \leftrightarrow \mathrm{H}^{+}+\mathrm{HCO}_{3}^{-}
$$

Dissociation of bicarbonate ion:

$$
\mathrm{HCO}_{3}^{-} \leftrightarrow \mathrm{H}^{+}+\mathrm{CO}_{3}^{2-}
$$

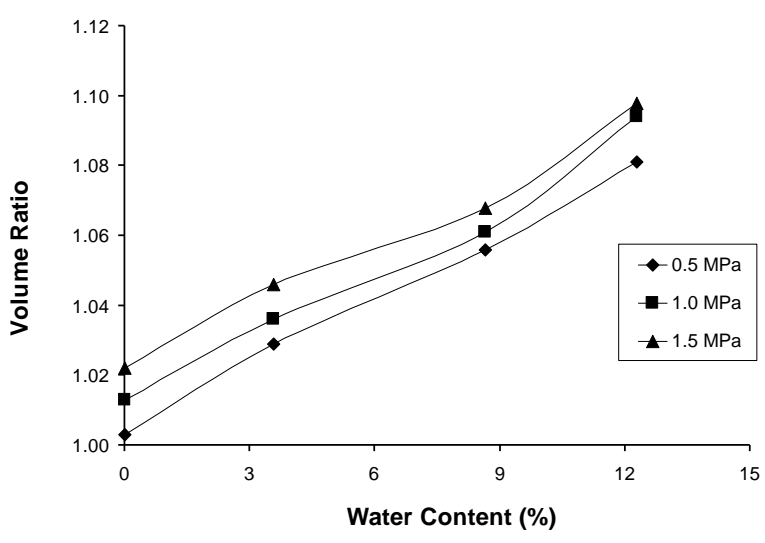

Fig. 7. Effect of water content on equilibrium volume ratio of oil/emulsion- $\mathrm{CO}_{2}$ system.

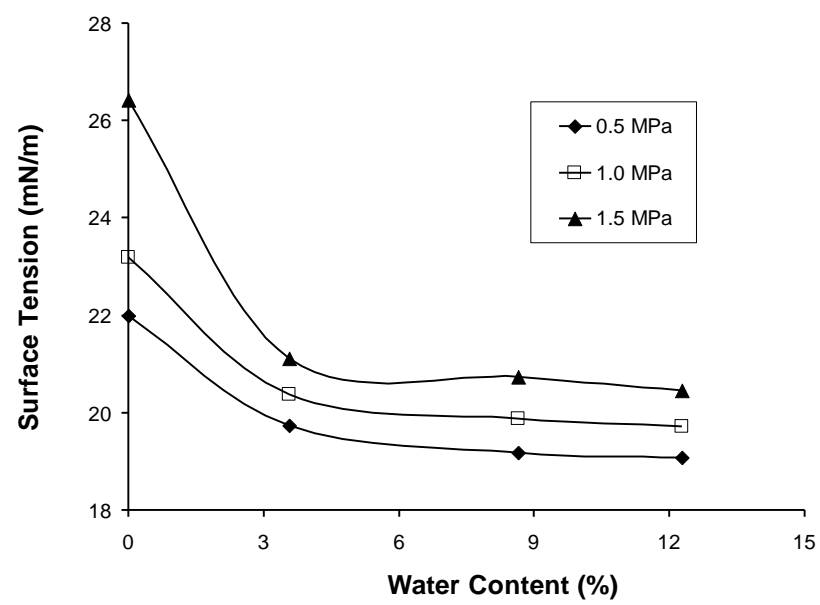

Fig. 8. Effect of water content on equilibrium IFT of oil/emulsion- $\mathrm{CO}_{2}$ system.

These reactions may enhance the solubility of $\mathrm{CO}_{2}$ in emulsion because of water in oil. Therefore more $\mathrm{CO}_{2}$ can be absorbed in emulsions, resulting in the oil swelling factor becoming larger and reduction of interfacial tension.

\section{CONCLUSION}

The oil swelling factors and interfacial tension of carbon dioxide in heavy oil and its emulsions are measured by applying the pendant drop volume analysis method. This method is beneficial for quick measurement of oil swelling factors and interfacial tension in heavy oil-solvent systems. The experimental results show that the oil swelling factors of heavy oil and its emulsions increase with pressure and water content in oil. However, the interfacial tension of those systems reduces as pressure and water content in oil become larger. This is because both physical and chemical absorptions of $\mathrm{CO}_{2}$ in oil and water occur. Physical absorption depends mainly on gas pressure. Therefore, high pressure can serve as a high driving force for $\mathrm{CO}_{2}$ solubility.

On the other hand, water can be conducive to oil swelling factors in such a way that water enhanced $\mathrm{CO}_{2}$ absorption into oil by chemical absorption. Among the four water oil ratios tested in this study, 12.27 percent w/o ratio had the largest effects on oil swelling effect and interracial tension compared to heavy oil at 0.0 percent w/o ratio at the same conditions.

\section{ACKNOWLEDGMENT}

The authors would like to acknowledge the International Training Program (ITP) supported by the Japan Society for the Promotion of Science (JSPS), as well as Novel Carbon Resource Sciences (NCRS), Global Center of Excellence (G-COE), Kyushu University, Japan for financial support. This work was carried out when the author was a Research Associate of the Research and Education Center of Carbon Resources at Kyushu University, Japan. Also, the authors wish to express their gratitude to the Enhanced Oil and Gas Recovery and Reservoir Characterization Research Group (EOGRRC), University of Alberta, Canada for collaboration.

\section{REFERENCES}

[1] M. B. Dusseault, "Comparing Venezuelan and Canadian heavy oil and tar sands," presented at the Petroleum Society's Canadian International Petroleum Conference, Calgary, Alberta, Canada, June 12-14, 2001.

[2] K. Kumar, A. D. Nikolov, and D. T. Wasan, "Mechanisms of stabilization of water-in-crude oil emulsions," Industrial \& Engineering Chemistry Research, vol. 40, pp. 3009-3014, 2001.

[3] C. Dicharry, D. Arla, A. Sinquin, A. Graciaa, and P. Bouriat, "Stability of water crude oil emulsions based on interfacial dilatational rheology," Journal of Colloid and Interface Science, vol. 297, pp. 785-791, 2006

[4] D. G. Thompson, A. S. Taylor, and D. E. Graham, "Emulsification and demulsification related to crude oil production," Colloids and Surfaces, vol. 15 , pp. 175-189, 1985

[5] P. Walstra, "Principles of emulsion formation," Chemical Engineering Science, vol. 48, pp. 333-349, 1993.

[6] R. M. Butler, Thermal Recovery of Oil and Bitumen, 1st ed. New Jersey, USA: Prentice Hall, 1991, ch. 4, pp. 125-129.

[7] D. Langevin, S. Poteau, I. Hénaut, and J. F. Argillier, "Crude oil emulsion properties and their application to heavy oil transportation," Oil \& Gas Science and Technology - Rev. IFP, vol. 59, pp. 511-521, 2004.

[8] D. Yang and Y. Gu, "Diffusion coefficients and oil swelling factors of carbon dioxide, methane, ethane, propane and their mixtures in heavy oil," Fluid Phase Equilibria, vol. 243, pp. 64-73, 2006

[9] F. K. Hansen and G. Rødsrud, "Surface tension by pendant drop i. a fast standard instrument using computer image analysis," Journal of Colloid and Interface Science, vol. 141, pp.1-9, 1991.

[10] D. Yang, P. Tontiwachwuthikul, and Y. Gu, "Interfacial interactions between reservoir brine and $\mathrm{CO}_{2}$ at high pressures and elevated temperatures," Energy and Fuels, vol. 19, pp. 216-223, 2005.

[11] P. V. Danckwerts and M. M. Sharma, "The absorption of carbon dioxide into solutions of alkalis and amines (with some notes on hydrogen sulfide and carbonyl sulfide)," The Chemical Engineer, vol. 10, pp. 244-278, 1966.

[12] A. L. Kohl and R. B. Nielsen, Gas Purification, 5th ed. Texas, USA Gulf Publishing, 1997, ch. 2, pp. 42-43. 


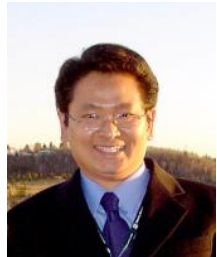

Kreangkrai Maneeintr is working as a lecturer in the Department of Mining and Petroleum Engineering, Chulalongkorn University, Bangkok, Thailand. He received Bachelor and Master Degrees in Chemical Engineering from Chulalongkorn University, Thailand and received Ph.D. Degree from University of Regina, Saskatchewan, Canada. Dr. Maneeintr's areas of interest are carbon capture, storage and utilization as well as unconventional oil and gas production

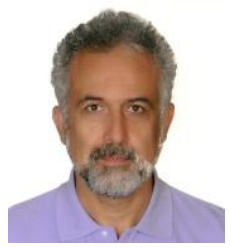

Tayfun Babadagli is a professor in the School of Mining and Petroleum Engineering at the University of Alberta where he holds an NSERC-Industrial Research Chair in "Unconventional Oil Recovery," sponsored by eight national and international companies. He previously served on the faculty at Istanbul Technical University, Turkey, and Sultan Qaboos University, Oman. Babadagli's areas of interest include modeling fluid and heat flow in heterogeneous and fractured reservoirs, reservoir characterization through stochastic and fractal methods, optimization of oil/heavy-oil recovery by conventional/unconventional EOR methods and $\mathrm{CO}_{2}$ sequestration. He holds $\mathrm{BS}$ and MS degrees from Istanbul Technical University and MSc and PhD degrees from the University of Southern California, all in petroleum engineering. He is currently the Executive Editor for SPE Reservoir Evaluation and Engineering (the formation-evaluation part) and as Associate Editor of the ASME Journal of Energy Resources Technology. Babadagli has served on the technical program and steering committees of 14 SPE conferences and forum series, and on SPE Education and Professionalism and SPE Career Guidance and Student Development committees.

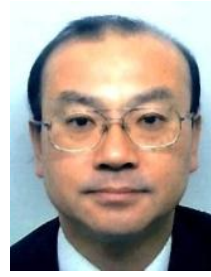

Kyuro Sasaki is a professor of Resources Production and Safety Engineering, Department of Earth Resources Engineering at the Faculty of Engineering, Kyushu University, Fukuoka, Japan. He holds B.Eng. M.Eng. and $\mathrm{PhD}$ (in Fluids Engineering) from Hokkaido University, Sapporo, Japan. His background is fluid engineering and production engineering, and current research areas include thermal fluids transport phenomena in mineral resources production, system design and numerical modelling in mining and petroleum engineering area. Dr. Sasaki has a professional experience in system design. Dr. Sasaki is a member of MMIJ, JAPT, and SPE.

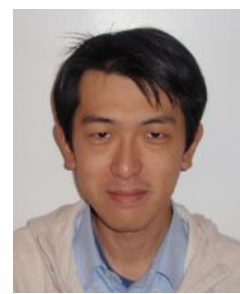

Yuichi Sugai is an assistant professor in the Department of Earth Resources Engineering, Faculty of Engineering, at Kyushu University in Fukuoka, Japan. He started his career in earth engineering with Tohoku University as a research associate in 2001 After two years, he moved to Venture Business Laboratory with Akita University as a post doctoral fellow. Later he joined Kyushu University in 2005 He has written and published several technical papers related to petroleum engineering. He holds a $\mathrm{Ph}$.D. degree from Tohoku University in earth engineering. 